\title{
An Economic Perspective on Crime and Punishment in Modern Australia
}

\author{
Brian Dollery and Joe Wallis
}

$\mathbf{R}$ ECENT election campaigns in New South Wales, Queensland and Western Australia have witnessed the emergence of law and order as an important Lelectoral issue. In their attempts to sway voters, politicians from virtually all the mainstream political parties have sought to persuade electors that they are comparatively 'tough on crime'. In some instances, competing politicians try to forge anti-crime credentials by calling for harsher sentences for many types of crime and limitations on early parole for convicted offenders.

In many respects this emphasis on crime and justice in Australian politics resembles a more established tradition in American politics, where candidates for public office now routinely denounce their opponents for being 'soft on crime' and almost unanimously support the death penalty for certain serious offences. Remember George Bush's successful 'revolving door' advertisement involving the notorious Willie Horton which badly undermined Governor Dukakis's presidential campaign in 1988 ?

The legal establishment has generally not welcomed the emergence of law and order as an electoral issue in Australia. Numerous commentators have condemned politicians from all parties for focusing on crime, especially candidates who call for harsher sentencing laws. For instance, Broadhurst and Loh have argued that the Western Australian Crime (Serious and Repeat Offenders) Sentencing Act 1992, which imposed higher penalties on juvenile criminals, was politically motivated: ' . . the government, in our thesis, was not primarily legislating to control dangerous young offenders at all - although it may have hoped or believed the Act would operate to catch and deter the "hard core" offender. Rather the government persisted with the legislation because it appeared to be tough and harsh on "hard core" offenders' (Broadhurst \& Loh, 1993:267). Similarly, Findlay has observed that 'in New South Wales both sides of politics prefer views on crime, control and prevention, which not only exaggerate the crime threat, but imply that short term, and dramatic political responses are the answer' (1995:325). Moreover, various experts have assured us that available data show that crime rates are not rising and that the streets are not any less safe than they used to be (see, for example, Grabovsky, 1995).

Sometimes the media are blamed for generating a public fear of crime disproportionate to the actual incidence of crime. Thus, Findlay has argued that 'all too

Brian Dollery is Senior Lecturer in Economics at the University of New England. Joe Wallis is Senior Lecturer in Economics at the University of Otago. 
often the media chooses to distort the reality of crime across a range of communities in the face of empirical evidence which supports the alternative view' (1995:325). It is also argued that even if crime rates do cause alarm and distress in the community, harsher sentences will not reduce the incidence of crime since the 'real causes' of criminal behaviour are to be found in the socioeconomic backgrounds of offenders, most notably 'alienation', material and psychological deprivation, and unemployment. Indeed, some commentators have even argued that many offenders, especially younger criminals, are themselves 'victims' of society and accordingly deserve compassion and not punishment.

Yet despite its widespread acceptance among criminologists, the conventional wisdom that, in general, punishment does not deter the crime can be questioned on both logical and empirical grounds.

\section{The Economic Theory of Crime}

Two generic approaches to crime and punishment can be found within the social sciences. On the one hand, criminologists, psychologists and others have argued that (in the words of two of their critics) 'criminals are not rational and are driven to commit crimes by influences outside their control' (Buchanan \& Hartley, 1992:48). Economists, on the other hand, have applied their standard model of homo economicus to the problem of crime and characterised criminal choice as a rational and calculated process. This approach follows Gary Becker's (1968:170) observation that a useful theory of crime does not require anything beyond the conventional economic analysis of rational behaviour.

The key difference between the two approaches to crime resides in the fact that whereas non-economic theories all provide deterministic explanations for criminal behaviour, the economic approach emphasises the role of individual choice. Although economists readily concede that an individual's environment can influence both his preferences and the options available to him, they nevertheless insist that people always have the freedom to choose between alternative courses of action. Economists do not deny that poor education, limited work opportunities, and numerous other environmental, psychological and biological factors may influence criminal activity. They simply argue that so long as there is an element of rational choice involved in criminal behaviour, actual or potential criminals will respond to changes in their choice environment, including changes in the probability of apprehension and the severity of punishment.

The origins of the modern economic analysis of crime may be traced back at least as far as the seminal work of Beccaria (1794/1971) and Bentham (1831/1838). Despite being restated in increasingly sophisticated mathematical terms, the essentials of this approach to crime and punishment have changed little in the intervening years. The economic theory of crime centres on the putative decision by rational individuals on the marginal allocation of their scarce time between illegal and other activities. Individuals will participate in criminal activity if the expected net benefit accruing from crime exceeds the expected net benefit derived from alternative legitimate activities. Rational individuals are thus modelled as weighing up the antici- 
the anticipated benefits and costs associated with some given form of crime and comparing the outcome against the outcomes of equivalent legal endeavours. The individual is thus seen as deciding how to allocate his or her scarce time, labour and other resources amongst competing activities, some of which may be criminal. Rational behaviour consists in selecting that course of action believed most likely to generate the highest return to the individual. Although outcomes are conventionally ranked in terms of wealth maximisation, this need not be the case: physical, psychic and other conceivable benefits may also be included.

The risk of detection, apprehension, conviction and punishment is simply one of the many possible kinds of costs that must be taken into consideration. The economic theory of crime is thus merely a special case of more general economic theory of resource allocation under constraints. In his classic contribution to the economics of crime, Becker (1968:176) observed that 'criminal behaviour becomes part of a much more general theory and does not require ad hoc concepts of differential association, anomie and the like, nor does it assume perfect knowledge, lightening-fast calculation, or any of the other caricatures of economic theory'.

The economic approach of crime thus provides a coherent analytical framework for explaining the level of criminal activity. The number of illegal offences committed in any given period depends on (among other things) the probability of conviction and the magnitude of punishment relative to the expected benefits flowing from a criminal act. Accordingly, potential criminals can be deterred from illegal activity by increases in the probability of detection, apprehension, conviction and punishment and also by increases in the severity of punishment attendant upon conviction. The probability of conviction and punislıment and the severity of punishment are thus simply two sides of the same expected costs-of-crime coin. A smaller probability of punishment can therefore be compensated for by increasing the severity of punishment to deter criminals and vice versa. As Becker (1968:178) has argued, 'the widespread generalisation that offenders are more deterred by the probability of conviction than by the punishment when convicted turns out to imply in the expected utility approach that offenders are risk preferrers, at least in the relevant region of punishments'.

The prediction that potential criminals can be deterred from committing offences by (among other things) increases in the severity of punishment has significant implications for the formation and implementation of criminal justice policies and for the wider debate on law and order in Australia. If the severity of punishment and the rate of apprehension of offenders are two factors that can reduce the incidence of crime by deterring potential criminals, this can significantly assist policy formulation. For example, it follows that we do not necessarily have to increase the rate of apprehension of criminals, which almost certainly involves a considerable and expensive increase in the number of police, in order to reduce the incidence of criminal behaviour. Increasing the severity of punishment while maintaining the current level of apprehension will also serve to reduce the incidence of crime. Although increasing the severity of punishment by means of, say, longer prison sen- 
tences is not a costless alternative to higher apprehension rates, it may well prove a cheaper means of achieving the intended reduction in crime rates.

Although deterrence is an important objective of legally inflicted punishment, it is by no means the only one. Other objectives, including incapacitation, rehabilitation, reparation and retribution, and the reinforcing of informal penalties and shared moral values, are also sought by criminal justice systems. Nevertheless, it is important to determine whether the central predictions of the economic approach do indeed have the support of evidence drawn from the real world.

\section{The Empirical Analysis of Crime}

Most empirical work based on the economic theory of crime consists of crosssection regression analyses which seek to find statistical correlations between crime rates and putative determinants of crime covering many categories of crime, regional areas and estimation techmiques. Here, we are especially interested in the quantitative effects of different factors in the criminal justice system on the incidence of crime. This methodology seeks to establish the effects of the probability of punishment, the severity of punishment, and other socioeconomic variables associated with the perceived incidence of crime on the actual crime rate.

The vast majority of studies in the area ${ }^{1}$ have focused on the United States. But useful work has also been conducted in Australia, Britain, Canada, Finland, India and Sweden. In general, available econometric evidence provides strong support for the economic theory of crime. Both the likelihood and the severity of punishment are statistically significant deterrents of crime, however it is measured. Erling Eide (1994:156) has summarised the outcome of empirical research on the economic theory of crime as follows:

As a whole, criminometric studies clearly indicate a negative association between crime and the probability and severity of punishment. The result may be regarded as a rather firm corroboration of the deterrence explanation in the theory of rational behaviour; an increase in the probability or severity of punishment will decrease the expected utility of criminal acts, and thereby the level of crime.

While the numerous empirical analyses of crime in this tradition have all employed different sets of data and embodied varying model specifications, they also demonstrate that the deterrent effect of certainty of puinishment is generally greater than the deterrent effect of the severity of punishment. However, the deterrent effects of the probability and the severity of punishment differ significantly between different kinds of crime.

\footnotetext{
${ }^{1}$ Several useful surveys of this voluminous empirical literature exist: see, for example, Lewis (1987), Cameron (1988), Eide (1994) and Pyle (1995).
} 
The statistical analysis of crime has at least two significant shortcomings. First, problems exist with the nature of the data on crime and punishment. ${ }^{2}$ For instance, most crimes are under-reported, and the extent of under-reporting is likely to vary considerably from one jurisdiction to the next, and, within a given jurisdiction, from one period and crime category to the next. Similarly, problems exist with police crime statistics and their relationship to court statistics on convictions and prison statistics on sentences actually served. Many investigators simply rely on aggregate data and hope the biases will not be significant enough to obscure the true underlying relationships. Second, bias arises from the simultaneous equations used in regression analyses of the data. For example, if crime in some community increases, then that community is likely to support harsher penalties as a means of coping with the heightened crime problem. In a statistical analysis, this could translate into a positive correlation between the level of crime and the severity of punishment, which distorts the apparent deterrent impact of punishment in the short run. Despite these problems in the statistical analysis of crime, the weight of evidence overwhelmingly supports the view that the crime rate is influenced by expected penalties.

Available evidence on other possible determinants of crime is much less conclusive. Various proxies, like median family income, median income, labour income to inanufacturing workers, mean family income, mean income per tax unit and mean income per capita, have been used to measure the benefits of legal activities. But no systematic relationship has been found between legal income opportunities and crime rates. Similarly, estimates of various measures of the economic gains to crime and their relationship to the level of criminal behaviour have generated ambiguous results. Moreover, the effects of income differentials within society on crime rates are statistically inconsequential.

Unemployment deserves special mention. Orthodox opinion in Australia and some European countries holds that unemployment is a significant 'cause' of crime since, in the absence of 'socially adequate' welfare payments, crime is an attractive alternative to a life of poverty. Indeed, interest groups often argue that one of the benefits of the increasingly expensive welfare state is that it limits the growth of criminal activity. Nevertheless, the available evidence shows little systematic relationship between unemployment and crime rates.

Various sociodemographic variables have also been tested, most often age, population density and race. Several studies have found youth to be a statistically significant determinant of crime. Similarly, a preponderance of research indicates that population density is positively correlated with criminal activity, although there may be reason to believe population density may reflect underlying influences, such as differences in the degree of social control. Race is also statistically significant, at least in the American national context: numerous studies find that the proportion of non-whites in a given population is statistically associated with high crime rates.

${ }^{2}$ See, for example, Haikler and Dagger (1993) for a discussion of these problems. 


\section{Concluding Remarks}

The recent emphasis on law and order issues in State election campaigns shows that politicians from across the political spectrum believe that voters are concerned about crime. The question of whether or not actual crime rates have indeed risen is largely beside the point. To be sure, controversy exists as to whether various measures of criminal activity, including victim surveys, reflect any increase in crime. But even if crime rates are not rising, growing public alarm surely shows that people are becoming less inclined to accept existing crime levels: an entirely legitimate popular sentiment to which politicians have legitimately responded.

The economic theory of crime assumes that potential criminals are essentially rational individuals who weigh up the expected benefits and costs of crime before engaging in criminal activity. There is strong evidence showing that raising the expected costs attached to criminal behaviour will reduce the incidence of crime, other things remaining constant. The economic approach to crime thus provides a rational basis for the development and implementation of criminal justice policies.

\section{References}

Beccaria, C. (1794/1971), 'On Crime and Punishment', in S. Grupp (ed.), Theories of Punishment, Indiana University Press, Bloomington.

Becker, G. (1968), 'Crime and Punishment: An Economic Approach', Joumal of Political Economy 76(2): 169-217.

Bentham, J. (1831/1838), 'Principles of Penal Law', pp.365-580 in J. Bowning (ed.), The Works of Jeremy Bentham, Vol. 1, Tait, Edinburgh.

Broadhurst, R. \& N. Loh (1993), 'The Phantom of Deterrence: The Crime (Serious and Repeat Offenders) Sentencing Act', Australia and New Zealand Jourial of Crimuiology 26(3): 251-71.

Buchanan, C. \& P. Hartley (1992), Criminal Choice: The Economic Theory of Crime and Its Implications for Crime Control, Centre for Independent Studies, Sydney.

Cameron, S. (1988), 'The Economics of Crime Deterrence: A Survey of Theory and Evidence', Kyklos 41 (2): $301-23$.

Eide, E. (1994), Economics of Crime: Detertence and the Rational Offender, North-Holland, Amsterdam.

Findlay, M. (1995), 'From the Director's Desk', Current Issues in Criminal Justice 6(3): 325-6.

Grabovsky, N. (1995), 'Fear of Crime and Fear Reduction Stategies', Current Issues in Criminal Jusice 7(1): 7-19.

Haikler, J. \& D. Dagger (1993), 'Improving Crime Statistics by "Correcting" for System Characteristics: A Methodological Note', Australia and New Zealand Journal of Criminology 26(2): 116-26.

Lewis, D. (1987), 'The Economics of Crime: A Survey', Economic Analysis and Policy 17: 195-219.

Pyle, D. (1995), 'The Economic Approach to Crime and Punishment', Journal of Interdisciplinary Economics 6(1): 1-22.

We would like to thank two anonymous referees and the Editor for helpful comments on an earlier draft of this note. 